\title{
Feature Extraction of Bisindo Alphabets Using Chain Code Contour
}

\author{
Dolly Indra $^{\# 1}$, Sarifuddin Madenda ${ }^{* 2}$, Eri Prasetyo Wibowo ${ }^{* 3}$ \\ ${ }^{\# 1}$ Faculty of Computer Science, Universitas Muslim Indonesia, Makassar, Indonesia \\ \#1 dolly.indra@umi.ac.id \\ ${ }^{* 2,3}$ Faculty of Computer Science, Gunadarma University, Jakarta, Indonesia \\ *2 sarif@staff.gunadarma.ac.id \\ *3eri@staff.gunadarma.ac.id
}

\begin{abstract}
This paper proposes a new method of features extraction of BISINDO (Indonesian Sign Language) alphabet forms. The extracted features play a very important role in the process of hand pattern recognition which expresses BISINDO alphabets and recognize letters when communicating. The proposed method consisted of 5 processes; segmentation, morphology closing, edge detection, contour following, and chain codes formation. 26 hand patterns representing the 26 BISINDO alphabets from $A$ to $Z$ are used during the experiments. The extracted features of each hand pattern (each BISINDO alphabet) are presented in terms of the probability value of occurrence of each chain code direction. The analysis result shows that every hand pattern expressing BISINDO letters has different features. This indicates that the extracted feature by the proposed method is very accurate to be used for BISINDO alphabets recognizing based on the hand pattern feature when communicating.
\end{abstract}

Keyword- Bisindo, Morphology Closing, Edge detection, Contour following, Chain Code

\section{INTRODUCTION}

In Indonesia, the deaf and dumb communicate using sign language. There are two types of sign language; Indonesian Sign Language (BISINDO) and Indonesian Sign Language System (SIBI). BISINDO was developed by deaf people themselves through Gerkatin (Indonesian Deaf Welfare Movement) whilst SIBI was developed by normal people instead of the deaf. SIBI is similar to the sign language used in America called ASL (American Sign Language) [1].

BISINDO alphabets are formed from handshapes [2]. Representing the alphabets A-Z in BISINDO, it can be performed with one hand or two hands. BISINDO alphabets using one hand are C, E, I, J, L, O, R, U, V and Z while alphabets using two hands are A, B, D, F, G, H, K, M, N, P, Q, S, T, W, X, and Y. So in the BISINDO alphabets, representing alphabets $\mathrm{A}-\mathrm{Z}$ are not uniform or heterogeneous.

It is necessary to do edge detection process to be able to translate the handshape in the BISINDO alphabets. The edge representation of an image significantly reduces the amount of data in the image that will be processed but does not change the real information of the image [3], [4]. At the end, the feature extraction process is performed.

Feature extraction is an important process in constructing each pattern classification which aims to get relevant information of each class characteristic [5]. An appropriate feature contains different information which is able to distinguish one object from the other.

A number of studies about pattern identification techniques or handshape which represents a particular letters or words have been described [6], [7], [8].

Shape features of an object describe characteristics of that object which are used to analyze an image in recognizing the shape of BISINDO alphabets. It is still difficult to translate the image of the handshape that has a heterogeneous form or multiform. Thus, it is important to find out a method which is effective and able to produce accurate shape features for all BISINDO alphabets (A-Z). This became the philosophical foundation of the method proposed in our study.

\section{METHOD}

In this section, the suggested method of shape features extraction of BISINDO alphabets is presented. In the method, there are 5 processes i.e.:

1. Segmentation.

2. Morphology closing.

3. Edge detection.

4. Contour following.

5. Formation of chain code.

The process for the proposed system is shown in Fig.1. Each process will be explained in the next section. 


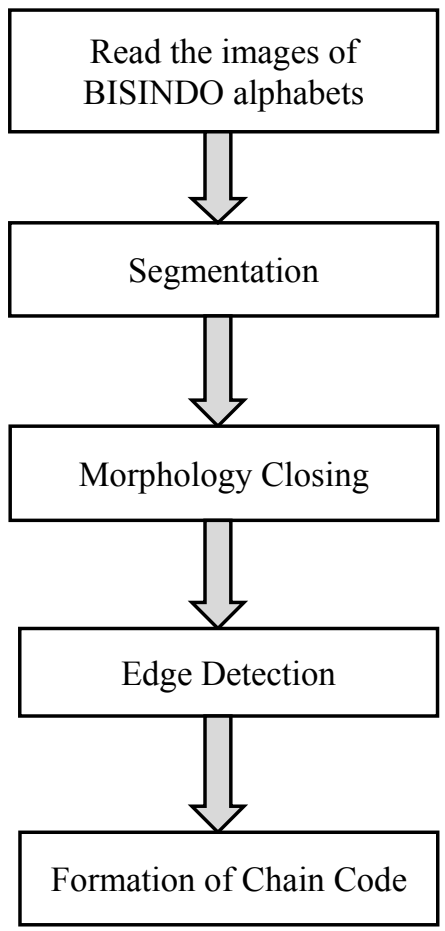

Fig. 1. Schema of the proposed system for the shape feature extraction of BISINDO alphabets

\section{A. Images of Bisindo Alphabets}

BISINDO alphabet images used are in RGB format (Red, Green, Blue). Handshape of the images representing BISINDO alphabets has different color to the background. The background used in this study is white. Fig. 2 shows 4 handshapes i.e.: A, B, C, D respectively. A, B, and D use two hands while C uses one hand. Based on Fig. 2, it can be seen that the hand color is used as the parameter to differentiate between the hand and background.

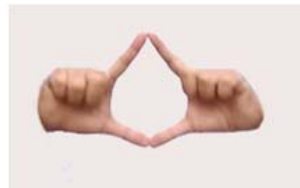

(a)

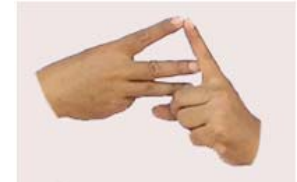

(b)

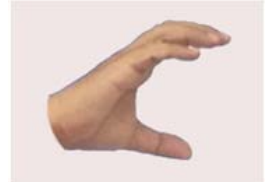

(c)

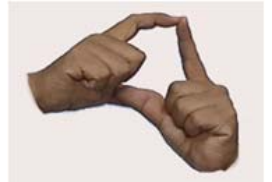

(d)

Fig. 2. Images of BISINDO alphabets (a) alphabet A, (b) alphabet B, (c) alphabet C, (d) alphabet D

\section{B. Segmentation}

Image segmentation process aims to extract objects of interest (OoI) from others which makes it easier to conduct the following analysis [9], [10], [11]. In the process of image segmentation, the most commonly used technique is the threshold value which is used to select the optimal threshold value to separate the desired object area from its background in the image based on gray-level. Thresholding has a very important role in the process of forming a binary image [12]. The segmentation process uses color distance measurement algorithm and threshold values to determine the similarity of skin tone with the colors of each pixel in the image. Referring to the images used is RGB color images, the formula distance used is city block distance or Manhattan distance which can be seen in the equation (1).

$$
\Delta E=\left|R_{s}-R_{p}\right|+\left|G_{s}-G_{p}\right|+\left|B_{s}-B_{p}\right|
$$

Where Rs, Gs, Bs, are red, green, blue color component of skin color whereas Rp, Gp, Bp, are red, green, blue color component of each pixel $\mathrm{P}$ color in the image. If the value of $\Delta E>T h$, then the pixel $\mathrm{P}$ is the part of the object area of interest.

In Fig. 3.(b)shows the result of the desired object segmentation that represents the shape of the Alphabet A (Fig. 3.(a)). Fig. 3.(c) is a gray-level image from an image of Fig. 3.(b). The result of segmentation using city block distance is not perfect yet due to some black holes in the fingers. This indicates that it needs another further action to cover the holes. 


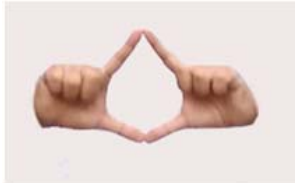

(a)

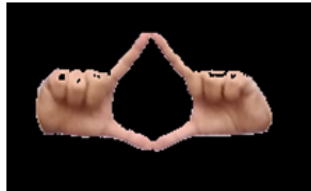

(b)

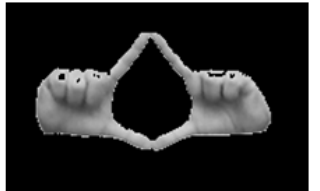

(c)

Fig. 3. (a) Original image, (b) Segmentation result, (c) Grayscale image from figure 3(b)

\section{Mathematical Morphology}

Mathematical morphology is one part of digital image processing used to analyze image [13]. Mathematical morphology uses techniques for digital image processing based on the shape of the object [14]. The mathematical morphology is commonly used the image processing both the binary image and gray-level image. The basic operation of mathematical morphology is dilation and erosion. Dilation is a morphological process to expand the area or size of an object. Dilation image of $f$ by the structure of element $B$ is shown in Equation 2. Erosion is a morphological process to erode or reduce the width of the surface size of an area or object. The erosion image of $\mathrm{f}$ by the element structure of matrix $\mathrm{B}$ shown in the equation 3 .

$$
\begin{aligned}
& f \oplus B=\left\{s \mid(B)_{s} \cap f \neq 0\right\} \\
& f \ominus B=\left\{s \mid(B)_{s} \subseteq f\right\}
\end{aligned}
$$

From these operations, then two other processes were developed, closing and opening. Closing and opening are used as morphological filtering in digital image processing [15]. Closing was the combination of the dilation process and erosion process conducted successively. The dilation result was as the input for the erosion operation as shown in the equation 4. Closing functioned to cover the holes throughout dilation operation and to prevent the change of the object size through erosion operation.

$$
f \cdot B=(f \oplus B) \ominus B
$$

Fig. 4.(b) shows the binary image which was resulted from the closing process from Fig. 4.(a). It is clear that all holes have been covered without any extension of the object area.

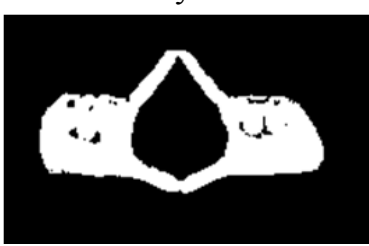

(a)

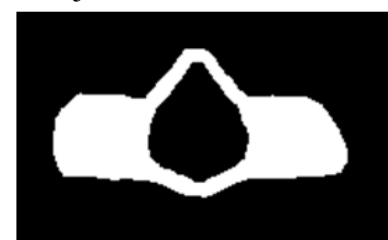

(b)

Fig. 4. (a) Binary image, (b) Binary image was resulted from the closing process

\section{Edge Detection}

Edge detection is an image processing technique used to identify and discover sharp discontinuities or to identify object boundaries in an image [16], [17]. The boundaries can be seen due to the intensity differences or the different color between one pixel with the closest neighbor pixels.

In this study, we use the Roberts operator as edge detection. The operator consists of a pair of $2 \times 2$ convolution mask is shown in Fig. 5. The results of the edge detection process of the image in the Fig. 4.(b) with use Roberts operator are shown in Fig. 6. Fig. 7 shows the result of edge detection process of alphabet B, C, and $\mathrm{D}$.

\begin{tabular}{|c|c|}
\hline-1 & 0 \\
\hline 0 & 1 \\
\hline \multicolumn{2}{|c|}{$\mathrm{G}_{\mathrm{x}}$} \\
\hline
\end{tabular}

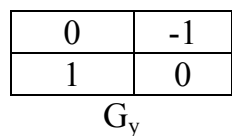

Fig. 5. Roberts mask

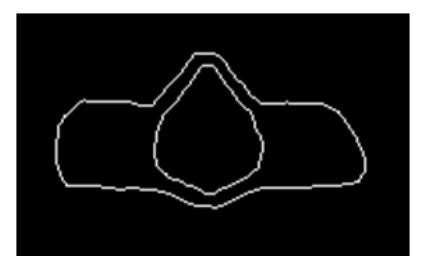

Fig. 6. Image of the edge detection processing for alphabet $A$ 


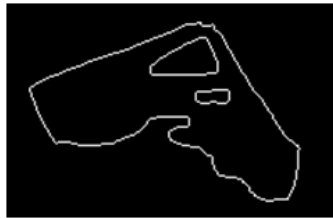

(a)

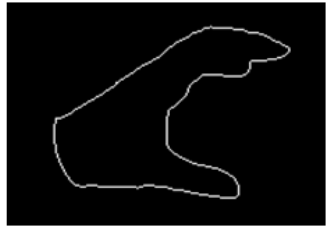

(b)

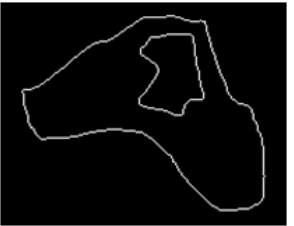

(c)

Fig. 7. Image of the edge detection result of BISINDO alphabet of B, C, D

\section{E. Contour Following}

Contour is a segment that has a width of one pixel and has a length of one or more pixels while the boundary is an interconnected or uninterrupted contour [18]. Identification of contour or contour extraction is a very important part to analyze the contents of an image.

Contour following is a method to find out the start point of the object edge and then follow it forward to the end of the edge. The following forward technique to determine the movement direction of the contour conducted by using eight neighbor pixels. In our case, the entire contour objects were represented by white pixels where the thickness of the contour was one pixel. The process of the contour following as below:

1.Check each pixel in each row for each column. Either it was the part of the contour or not. If the start point of the contour was found then the second stage was taken, however if it was not found then the fourth stage was taken.

2. Do the following forward trace by using eight neighbor pixels to determine the next contour pixel. Do it continuously to the last pixel from this contour.

3. Return to the first stage to find out the other contour.

4. The following is completed.

\section{F. Chain Code}

Chain code is used to represent the shape of the contour of the object by using the direction code of the contour movement. The chain code gives the boundary of the characteristics of an image which representing the direction in which pixel is located and has a connection to the starting point [19]. The method for finding contours is also called the Freeman chain code [20]. In this study, we used the eight-direction chain code.

As mentioned above that the contour movement is searched by the approximate direction of the eight neighboring pixels as shown in Fig. 8. The center point is the contour pixel which is tracked by the coordinates $(\mathrm{x}=0, \mathrm{y}=0)$, the next pixel shows the direction of the contour motion encoded with $0-7$ as shown in Table I.

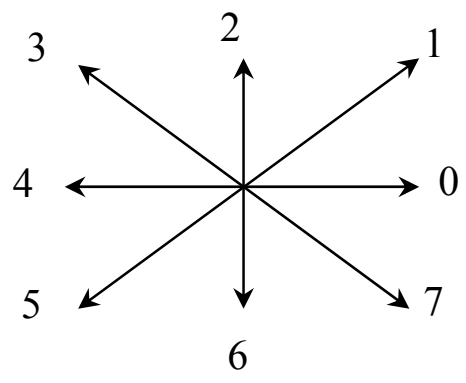

Fig. 8. Eight-direction chain code

TABLE I Direction of contour movement with chain code

\begin{tabular}{|c|c|c|}
\hline $\mathbf{d x}$ & $\mathbf{d y}$ & Chain Code \\
\hline+1 & 0 & 0 \\
\hline+1 & -1 & 1 \\
\hline 0 & -1 & 2 \\
\hline-1 & -1 & 3 \\
\hline-1 & 0 & 4 \\
\hline-1 & +1 & 5 \\
\hline 0 & +1 & 6 \\
\hline+1 & +1 & 7 \\
\hline
\end{tabular}


In this study, we modify the chain code because BISINDO alphabets have different contours i.e. if there is more than one contour then each contour will be added number 9 as a boundary between the contour one and the other contour.

The chain code contours of the BISINDO alphabets A, B, C, and D in Fig. 6 and 7 are shown in Fig. 9 to 12. Alphabets A and D have two contours so there is only one ' 9 ' as the boundary, the alphabet $B$ has three contours so there are two ' 9 ' as boundaries, while the alphabet $\mathrm{C}$ has only one contour no boundary.

\begin{tabular}{|l|}
\hline 00000000007077776767776770776776770777000000000000170 \\
00000000000000007070707067776776776776676767667666666 \\
65565644544444544444444444444544444444444444444444444 \\
44544544545454545454544544344444444344343434343443444 \\
34444444434444445444434444443444444444444444442332322 \\
3223222222222222122222211212011111101700000000000000 \\
0000000070070000000121111121111111121121112190000077 \\
67767767777677677777076766766676776676666656665666545 \\
55545454545454454554444433434344433434443433333322232 \\
222222122221221212211111112112111121121121
\end{tabular}

Fig. 9. Chain code of BISINDO for alphabet A

00670000017667077767676767767676776767677767676776777 77767677677766776776776777707770675666666666665666665 66656565656444444445444434434342343223334234434444443 44432332232222344333334444434444344343423222101010000 00122223444444444444444444544455655555455445445454455 44444445444444444444434443444444453323323233232323232 32232232322322101101010101001001010100100100101010010 01001001001000100100101010010100101001001010010101010 10000001900007676767676676766666654444454444444444444 44444444444444444443222210111101011010101011010010101 9000000000766666554444434445444443432222100000000

Fig. 10. Chain code of BISINDO for alphabet B

700000000000070000007070000007007070770700770707665554 544544444544444444456666565545444444444443444444444444 555545556566565555555545566656666666666666666667677770 770707070700700007000700070707077077676766666655444444 444344444434444434444344434444443443444444434444445445 344444444444444444444444344444454443443333233232323232 232232222232222222222221222000101010111010110110101101 011101101120110110110111011010101101011111110111010101 01110010011000

Fig. 11. Chain code of BISINDO foralphabet $\mathrm{C}$

000007000707000700000017006676666766766676667667676667667 667667676767667666767767077700070077766766667767666677667 666667666666666666666666667566666666666666565554455454444 444544444444444433434333333333333333332333323323232342232 343333333333334334334444344444444344444444445444444544445 444544544444544444444444444454443333232342323222223223223 22222223210000010100110111011111011101111111101111011101 101001000001010110111011101011101101000000000000000190000 000000000000776666766666666766666676676666667666676676666 544444444555566566654444434343443444443444434434322221111 12112112112121222323343334334322221011211210000001000

Fig. 12. Chain code of BISINDO for alphabet D 


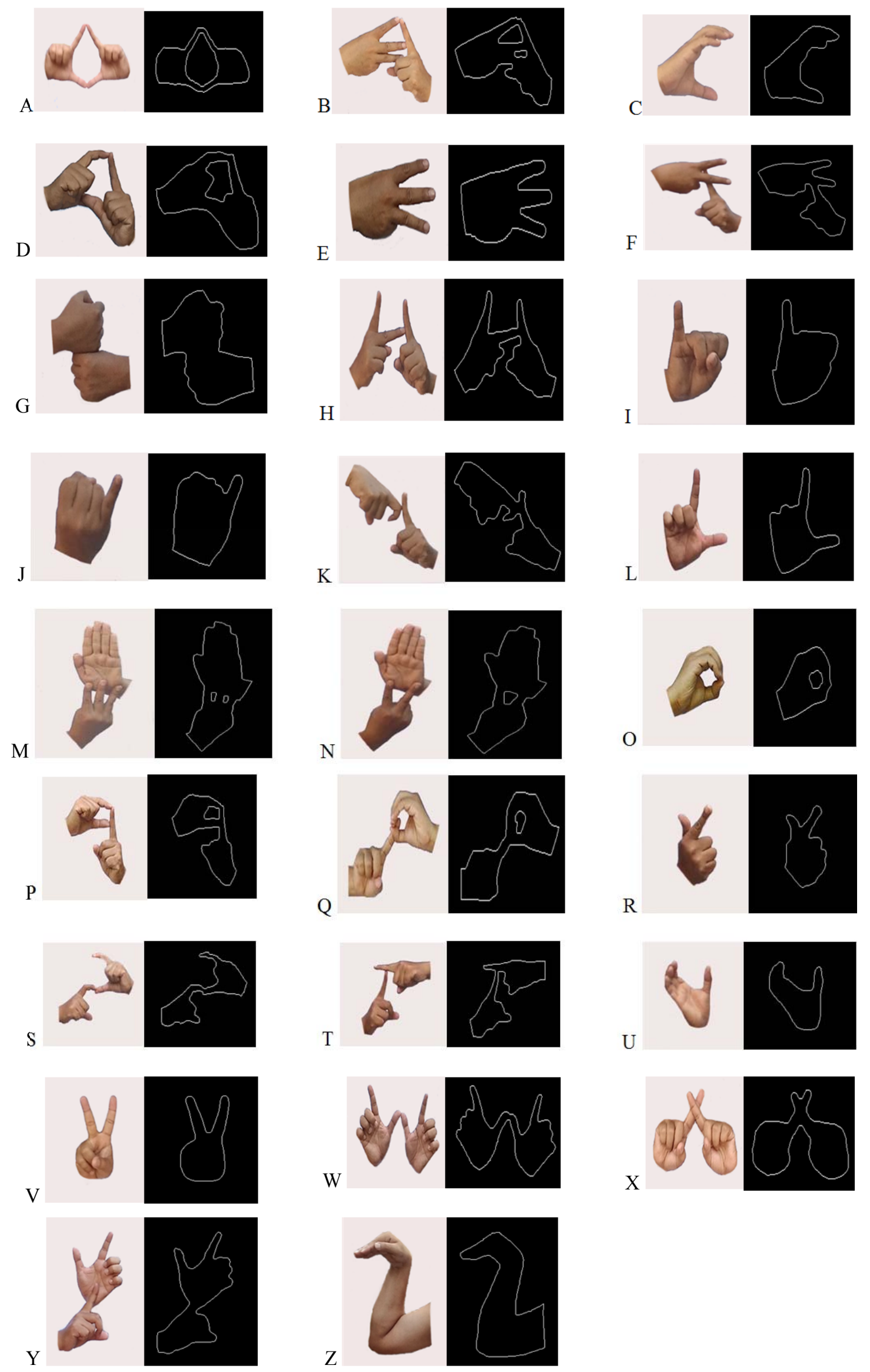

Fig. 13. The extraction result and edge detection of BISINDO alphabets (A- Z) 


\section{RESULTS AND ANALYSIS}

The suggested method and algorithm resulted a clear edge in one-pixel width. This eases to extract the chain code contour of the handshape that represents BISINDO alphabets. Fig. 13 shows the edge result of the BISINDO alphabets from $A$ to $Z$. The BISINDO alphabets can be classified according to the number of contours; C, E, F, G, H, I, J, K, L, R, S, T, U, V, W, X, Y, and Z have one closed contour, A, D, N, O, P, and Q have two closed contours, whereas $\mathrm{B}$ and $\mathrm{M}$ have three closed contours. The contours shaping each alphabet have different chain codes. Therefore, the feature number of the contour of each alphabet and the chain code in each contour can be used as the feature in the process of recognizing the BISINDO alphabets.

The problems in the object size or hand image size were sometimes smaller or bigger during the image acquisition. The size change caused the different length of the chain code even though the shape of the alphabets were still similar. Therefore, in this study, the probability feature of each code in each contour is used to make the chain code independent from the object size change. The probability of each chain code and the contour number (Table II) as a feature in each alphabet is saved in the database which would be used in the process of recognizing BISINDO alphabets.

TABLE II Probability each chain code

\begin{tabular}{|c|c|c|c|c|c|c|c|c|c|}
\hline Images & $\begin{array}{c}\text { Object } \\
\text { Features }\end{array}$ & $\mathbf{0}$ & 1 & 2 & 3 & 4 & 5 & 6 & 7 \\
\hline \multirow{2}{*}{ A.png } & 1 & 0.2176 & 0.0937 & 0.0854 & 0.0468 & 0.3306 & 0.0468 & 0.0661 & 0.1129 \\
\hline & 2 & 0.0382 & 0.1465 & 0.1592 & 0.0955 & 0.1529 & 0.0955 & 0.1592 & 0.1529 \\
\hline \multirow{3}{*}{ B.png } & 1 & 0.1829 & 0.1019 & 0.0833 & 0.1042 & 0.2384 & 0.0579 & 0.1157 & 0.1157 \\
\hline & 2 & 0.1649 & 0.1753 & 0.0412 & 0.0103 & 0.3814 & 0.0206 & 0.134 & 0.0722 \\
\hline & 3 & 0.3542 & 0.0208 & 0.0833 & 0.0625 & 0.2917 & 0.0625 & 0,1064 & 0.0208 \\
\hline C.png & 1 & 0.2063 & 0.1300 & 0.0673 & 0.0561 & 0.2848 & 0.0807 & 0.0919 & 0.0830 \\
\hline \multirow{2}{*}{ D.png } & 1 & 0.1596 & 0.1197 & 0.0665 & 0.1353 & 0,1973 & 0.0355 & 0.1973 & 0,0887 \\
\hline & 2 & 0.1520 & 0.117 & 0.1111 & 0.0994 & 0.1973 & 0.0409 & 0.2398 & 0.0887 \\
\hline E.png & 1 & 0.3354 & 0.0475 & 0.0823 & 0.0506 & 0.3006 & 0.0791 & 0.0601 & 0.0443 \\
\hline F.png & 1 & 0.3038 & 0.0615 & 0.0538 & 0.0885 & 0.2846 & 0.0692 & 0.0654 & 0.0731 \\
\hline G.png & 1 & 0.1640 & 0.0760 & 0.1880 & 0.0560 & 0.1920 & 0.0640 & 0.1920 & 0.0680 \\
\hline H.png & 1 & 0.1153 & 0.1216 & 0.1611 & 0.0869 & 0.1438 & 0.0932 & 0.1927 & 0.0853 \\
\hline I.png & 1 & 0.1692 & 0.0498 & 0.2687 & 0.0398 & 0.1095 & 0.1294 & 0.1791 & 0.0547 \\
\hline J.png & 1 & 0.1383 & 0.1011 & 0.2181 & 0.0532 & 0.1117 & 0.1436 & 0.1702 & 0.0638 \\
\hline K.png & 1 & 0.0827 & 0.0746 & 0.1783 & 0.1329 & 0.1442 & 0.0648 & 0.1394 & 0.1831 \\
\hline L.png & 1 & 0.1801 & 0.0616 & 0.2180 & 0.0521 & 0.1517 & 0.1043 & 0.1706 & 0.0616 \\
\hline \multirow{3}{*}{ M.png } & 1 & 0.0922 & 0.0700 & 0,3003 & 0.0768 & 0.0137 & 0.1314 & 0.2560 & 0.0597 \\
\hline & 2 & 0.1364 & 0,0227 & 0.3409 & 0.0227 & 0.0909 & 0.0682 & 0.2955 & 0.0227 \\
\hline & 3 & 0.1471 & 0.0294 & 0.2941 & 0.0294 & 0.1176 & 0.0882 & 0.2647 & 0.0294 \\
\hline \multirow{2}{*}{ N.png } & 1 & 0.0860 & 0.1017 & 0.2708 & 0.0688 & 0.0315 & 0.1375 & 0.2536 & 0.0501 \\
\hline & 2 & 0.1707 & 0.0122 & 0.3171 & 0.0244 & 0.1098 & 0.1463 & 0.1341 & 0.0854 \\
\hline \multirow{2}{*}{ O.png } & 1 & 0.1399 & 0.1678 & 0.1119 & 0.0490 & 0.2028 & 0.1329 & 0.1189 & 0.0769 \\
\hline & 2 & 0.2424 & 0.0303 & 0.1515 & 0.0909 & 0.1818 & 0.0909 & 0.1515 & 0.0606 \\
\hline \multirow{2}{*}{ P.png } & 1 & 0.1210 & 0.0854 & 0.1815 & 0.1068 & 0.1317 & 0.0534 & 0.2349 & 0.0854 \\
\hline & 2 & 0.1667 & 0.0714 & 0.1667 & 0.0238 & 0.2857 & 0.0238 & 0.1905 & 0.0714 \\
\hline \multirow{2}{*}{ Q.png } & 1 & 0.1973 & 0.1020 & 0.1474 & 0.0249 & 0.2540 & 0.0952 & 0.1043 & 0.0748 \\
\hline & 2 & 0.1228 & 0.0877 & 0.2281 & 0.0526 & 0.1228 & 0.1404 & 0.1579 & 0.0877 \\
\hline R.png & 1 & 0.1549 & 0.0845 & 0.1761 & 0.1197 & 0.0775 & 0.1479 & 0.1408 & 0.0986 \\
\hline S.png & 1 & 0.2054 & 0.0804 & 0.1116 & 0.0491 & 0.3080 & 0.0536 & 0.0714 & 0.1205 \\
\hline T.png & 1 & 0.2364 & 0.1045 & 0.1182 & 0.0455 & 0.2227 & 0.1136 & 0.1227 & 0.0364 \\
\hline U.png & 1 & 0.1788 & 0.0993 & 0.0927 & 0.1589 & 0.1126 & 0.0861 & 0.1987 & 0.0728 \\
\hline
\end{tabular}




\begin{tabular}{|c|l|l|l|l|l|l|l|l|l|} 
V.png & 1 & 0.0684 & 0.0895 & 0.2421 & 0.0737 & 0.1158 & 0.0579 & 0.2684 & 0.0842 \\
\hline W.png & 1 & 0.1049 & 0.0885 & 0.2164 & 0.1148 & 0.0557 & 0.1246 & 0.2066 & 0.0885 \\
\hline X.png & 1 & 0.1862 & 0.0729 & 0.1579 & 0.1093 & 0.1296 & 0.0972 & 0.1741 & 0.0729 \\
\hline Y.png & 1 & 0.0837 & 0.1255 & 0.2205 & 0.0456 & 0.1293 & 0.1255 & 0.1825 & 0.0875 \\
\hline Z.png & 1 & 0.1271 & 0.1271 & 0.1512 & 0.0481 & 0.2165 & 0.0584 & 0.2062 & 0.0653 \\
\hline
\end{tabular}

\section{IV.CONCLUSION}

The suggested method in this study consists of the algorithm for segmentation, closing operation, edge detection, contour following and chain code contour. The method is very effective and produce the edge with a thickness of one pixel. It facilitate the chain code extraction to get the probability which would be used as feature of each BISINDO alphabets. These features were saved in the database to become the feature references in the recognizing process of BISINDO alphabets.

\section{REFERENCES}

[1] N.Sugianto, F. Samopa, "Analisa manfaat dan penerimaan terhadap Implementasi Bahasa Isyarat Indonesia pada latar belakang komplek menggunakan Kinect dan Jaringan Syaraf Tiruan (Studi Kasus SLB Karya Mulia 1)”, JUISI, Vol. 01, No. 01, Februari 2015.

[2] Idris Kautsar, Rohmat Indra Borman, Ari Sulistyawati, "Aplikasi Pembelajaran Bahasa Isyarat Bagi Penyandang Tuna Rungu Berbasis Android Dengan Metode Bisindo", Seminar Nasional Teknologi Informasi dan Multimedia 2015.

[3] Muthukrishnan.R , M.Radha, "Edge Detection Techniques For Image Segmentation", International Journal of Computer Science \& Information Technology (IJCSIT) Vol 3, No 6, pp. 259-267, 2011.

[4] R.Maini, H. Aggarwal, "Study and comparison of various image edge detection techniques" , International Journal of Image processing (IJIP), volume (3), issue (1), pp. 1-12, 2009.

[5] Gaurav Kumar, Pradeep Kumar Bhatia, "A Detailed Review of Feature Extraction in Image Processing Systems “, IEEE, Fourth International Conference on Advanced Computing \& Communication Technologies, pp. 5-12, 2014.

[6] Bassem Seddik, Sami Gazzah, Najoua Essoukri Ben Amara,"Modalities Combination for Italian Sign Language Extraction and Recognition", Springer International Publishing Switzerland 2015, pp. 710-721, 2015.

[7] M. Zadghorban, Manoochehr Nahvi, "An algorithm on sign words extraction and recognition of continuous Persian sign language based on motion and shape features of hands", Springer-Verlag London 2016

[8] Sutarman, M. A. Majid, J. M. Zain, “A Review on the Development of Indonesian Sign Language Recognition System," J.Comput. Sci., vol. 9, no. 11, pp. 1496-1505, 2013.

[9] Rafika Harrabi, Ezzedine Ben Braiek, "Color Image Segmentation by Multilevel Thresholding using a Two Stage Optimization Approach and Fusion", International Journal of Engineering and Innovative Technology (IJEIT) Volume 3, Issue 11, May 2014.

[10] Hari Kumar Singh, Shiv Kumar Tomar, Prashant Kumar Maurya, "Thresholding Techniques applied for Segmentation of RGB and multispectral images", Proceedings published by International Journal of Computer Applications, MPGI National Multi Conference (MPGINMC-2012), 2012.

[11] Amit D. Purohit, S. T. Khandare, "A Survey On Different Color Image Segmentation Techniques Using Multilevel Thresholding “, International Journal of Computer Science and Mobile Computing, Vol.6 Issue.4, pp. 267-273, April 2017.

[12] Hetal J. Vala, Astha Baxi, "A Review on Otsu Image Segmentation Algorithm", International Journal of Advanced Research in Computer Engineering \& Technology (IJARCET), Volume 2, Issue 2, hal. 387-389, 2013.

[13] M. Rama Bai, "A New Approach for Border Extraction Using Morphological Methods", International Journal of Engineering Science and Technology, Vol. 2(8), pp. 3832-3837, 2010.

[14] K.Sreedhar, B.Panlal, "Enhancement Of Images Using Morphological Transformations",International Journal of Computer Science \& Information Technology (IJCSIT) Vol 4, No 1, pp.33-50, 2012.

[15] Beant Kaur, Sangeet Pal Kaur, "Applications of Mathematical Morphology in Image Processing: A Review “, International Journal of Electronics \& Communication Technology, IJECT Vol. 4, Issue Spl - 3, pp.15-17, 2013.

[16] Ireyuwa. E. Igbinosa, "Comparison of Edge Detection Technique in Image Processing Techniques “, International Journal of Information Technology and Electrical Engineering, Volume 2, Issue 1, pp.25-29, 2013.

[17] Ruohui Wang, "Edge Detection Using Convolutional Neural Network “, Springer International Publishing Switzerland , pp. 12-20, 2016.

[18] Jonghoon Seo, Seungho Chae, Jinwook Shim, Dongchul Kim, Cheolho Cheong, Tack-Don Han. "Fast Contour-Tracing Algorithm Based on a Pixel-Following Method for Image Sensors", MDPI, 2016.

[19] Dewi Nasien, Habibollah Haron, Haswadi Hasan and Siti S. Yuhaniz. (2010), "Chain Code Extraction of Handwritten Recognition using Particle Swarm Optimization“. Journal of Intelligent Computing Volume 1 Number 4, 2010.

[20] R S Vaddi, L N P. Boggavarapu, H D Vankayalapati, K. R. Anne, " Contour Detection Using Freeman Chain Code And Approximation Methods For The Real Time Object Detection", Asian Journal Of Computer Science And Information Technology1:1, pp. $15-17,2011$. 


\section{AUTHOR PROFILE}

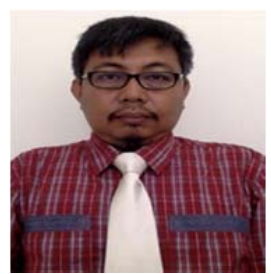

Dolly Indra was born in Tanjung Karang, Indonesia on 1974. Currently lecturer of Departement of Informatics Engineering, Faculty of Computer Science, Universitas Muslim Indonesia in Makassar, Indonesia. His current research interest are Image processing and Microcontroller. Email : dolly.indra@umi.ac.id

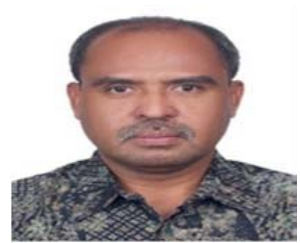

Prof. Sarifuddin Madenda - Currently Director of High School of Computer Science and Management Jakarta (STMIK Jakarta STI\&K). He received the B.S. degree from University of Indonesia, in 1989, the M.S. degree from Institute National des Sciences Appliquées de Lyon (INSA de Lyon) - French, in 1992, and the Ph.D. degree from University of Burgundy - French, in 1995. From 1995 to 1996, he was a Research Associate at LIESIB Laboratory - University of Burgundy. In 1997, he became a Lecturer in Computer Science Department, Gunadarma University - Indonesia. From 2002 to 2007, he was a researcher at Academic Research Consortium on digital imaging, video, audio and multimedia (CoRIMedia), Canada. His research interests are image processing: image compression, color imaging, image database and searching, medical image analysis, implementing of image processing algorithms on FPGA for real-time image analysis. Email: sarif@staff.gunadarma.ac.id

Eri Prasetyo Wibowo born in Kendal, Indonesia, in 1966. He received the B.S degree in Electronics and Instrumentation from Gadjah Mada University, Indonesia, in 1992, the M.S. degree in Information System from Gunadarma University, Indonesia, in 1994 and The Ph.D. degree in Electronics Informatics from the Burgundy University, France, in 2005. He is the member of IEEE, ACM, and Professional Organization in the field of Information and Computer Technology (IPKIN), APTIKOM. He has been worked as Secretary of Doctoral Program in Information Technology at Gunadarma University. He was the member of EACOVIROE Project to promoted Master VIBOT which founded by Erasmus Mundus. His current interests are in Real-time Image processing applications and System On CHIPs Design.

Email: eri@staff.gunadarma.ac.id 